\title{
Arahan Pengembangan Destinasi Wisata Kawasan Kaldera Batur Berbasis Sistem Informasi Geografis (SIG)
}

\author{
Nyoman Arto Suprapto ${ }^{1)}$; Moh. Agus Sutiarso ${ }^{2)}$ \\ 1) Dosen DIV Manajemen Pariwisata, STPBI \\ ${ }^{2)}$ Dosen DIV Manajemen Pariwisata, STPBI \\ E-mail: artosuprapto@stpbi.ac.id
}

\begin{abstract}
Abstrak
Kawasan Kaldera Batur memiliki beragam potensi pengembangan wisata namun juga sangat dibatasi pengembangannya karena kawasan ini ditetapkan sebagai kawasan konservasi di dalam rencana tata ruang Kabupaten Bangli dan Provinsi Bali. Pengembangan Kawasan dilakukan untuk mengkomodasi kepentingan ekonomi masyarakat namun sekaligus juga menjaga fungsi lindung kawasan tersebut. Dualisme fungsi kawasan tersebut mengharuskan adanya sebuah pendekatan yang yang tepat dalam mengembangkan destinasi wisata Kaldera Batur agar tercapai pembangunan pariwisata yang berkelanjutan. Salah satunya adalah pengembangan destinasi wisata berbasis Sistem Informasi Geografis (SIG). Arahan pengembangan destinasi wisata khususnya penyediaan fasilitas pariwisata pada Kawasan Kaldera Batur dilakukan dengan pendekatan kemampuan lahan yang dianalisis dengan Teknologi SIG. Berdasarkan hasil analisis ditemukan bahwa kelas kemampuan lahan pada Kawasan Kaldera Batur yang cocok untuk pengembangan fasilitas penunjang pariwisata adalah Kelas D dan E yaitu kelas lahan dengan kemampuan pengembangan agak tinggi dan tinggi seluas 14.096 Ha yang tersebar di Desa Batur Tengah, Batur Selatan, Songan A, Sukawana dan Abangbatudinding.

Kata kunci: pengembangan pariwisata, SIG, pariwisata berkelanjutan, kawasan kaldera batur

Abstract

The Batur Caldera has a variety of tourism development potentials but designated as a conservation area in the spatial plan for Bangli Regency and Bali Province cause a limited development allowed for thi destination. Development is carried out to accommodate the economic interests of the community while at the same time maintaining the protected function of the area. The dualism of the function of the area requires an appropriate approach in developing the Batur Caldera tourist destination in order to achieve sustainable tourism development. One of them is the development of tourist destinations based on Geographical Information Systems (GIS). The direction of developing tourist destinations, especially the provision of tourism facilities in the Batur Caldera Area, is carried out by using the land capability approach analyzed by GIS Technology. Based on the results of the analysis, it was found that the land capability classes in the Batur Caldera Area that are suitable for the development of tourism support facilities are Class $D$ and E, namely land classes with a rather high and high development capability covering an area of 14,096 hectares which are scattered in Batur Tengah Village, South Batur, Songan A, Sukawana and Abangbatudinding.
\end{abstract}

Keywords: tourism development, GIS, sustainable tourism, Batur caldera area 


\section{PENDAHULUAN}

Daya tarik wisata merupakan komponen utama dalam sistem kepariwisataan yang memunculkan permintaan untuk perjalanan wisata (Pitana dan Diarta, 2009). Bali adalah salah satu tujuan wisata internasional yang memiliki berbagai jenis daya tarik wisata seperti daya tarik wisata alam, daya tarik wisata budaya dan daya tarik wisata buatan. Potensi wisata yang ada di Bali tersebar di semua kabupaten/kota. Menurut Statistik Pariwista Bali (2017), 46\% kunjungan wisatawan ke Bali masih terkonsentrasi di Bali selatan (Tanah Lot, Uluwatu, Pantai Pandawa, Pantai Labuan Sait, dan Denpasar), sedangkan potensi pengembangan daya tarik wisata tersebar di setiap kabupaten/kota. Hal ini menyebabkan setiap kabupaten/kota di Bali berupaya mengembangkan produk wisata mereka agar lebih menarik, unik, dan beragam agar wisatawan mendapatkan berbagai produk wisata alternatif, sehingga tertarik mengunjungi daya tarik wisata yang mereka miliki.

Kabupaten Bangli adalah salah satu kabupaten yang memiliki potensi wisata alam yang sangat mengagumkan, salah satunya adalah Kawasan Kaldera Batur. Tercatat 70,2\% (555.602) wisatawan yang datang ke Kabupaten Bangli pada Tahun 2017 adalah untuk mengunjungi destinasi tersebut (Statistik Pariwisata Bali, 2017). Pada tahun 2017, Kawasan Kaldera Batur termasuk empat besar destinasi wisata yang dikunjungi wisatawan di Bali, meliputi Tanah Lot, Uluwatu, Ulundanu Beratan, dan Kintamani. Dengan demikian Kawasan Kaldera Batur memiliki peluang untuk mengembangkan produk wisata agar lebih menarik dan bervariasi dengan memanfaatkan potensinya.

Berbagai upaya dilakukan oleh pemerintah daerah untuk mengembangkan produk wisata pada Kawasan Kaldera Batur diantaranya merekomendasikan kawasan ini sebagai Kawasan Strategis Pariwisata Nasional (KSPN) dalam Rencana Induk Pembangunan Kepariwisataan Nasional (RIPKN) Tahun 2010-2025 dan mengajukan kawasan ini sebagai bagian dari Global Geopark Network (GGN) yang disetujui pada tahun 2012 (UNESCO, 2015). Status GGN ini juga menjadi branding kawasan untuk meningkatkan jumlah kunjungan di Kawasan Kaldera Batur. Sementara status kawasan sebagai KSPN akan memberikan keuntungan terhadap prioritas penataan dan pengembangan berbagai infrastruktur yang diperlukan untuk memenuhi standar Kawasan kaldera Batur sebagai Destinasi Wisata.

Berdasarkan Rencana Tata Ruang Wilayah (RTRW) Provinsi Bali Tahun 2009 - 2029 dan RTRW Kabupaten Bangli Tahun 2013-2033 sebagian besar penggunaan lahan di kawasan ini adalah berfungsi lindung sehingga pengembangan destinasi wisata (penyediaan fasilitas penunjang pariwisata) sangat dibatasi, meskipun kawasan ini memiliki berbagai potensi pengembangan yang sangat baik. Dualisme fungsi kawasan tersebut mengharuskan adanya sebuah pendekatan yang yang tepat dalam mengembangkan destinasi wisata agar tercapai pembangunan pariwisata yang berkelanjutan. Salah satunya adalah pengembangan destinasi wisata berbasis Sistem Informasi Geografis (SIG).

SIG adalah suatu sistem berbasis komputer yang memiliki kemampuan dalam menangani data bereferensi geografi yaitu pemasukan data, manajemen data (penyimpanan dan pemanggilan kembali), manipulasi dan analisis data, serta keluaran sebagai hasil akhir (output). Hasil akhir (output) dapat dijadikan acuan dalam pengambilan keputusan pada masalah yang berhubungan dengan geografi (Aronoff, 1989). Sejauh ini SIG lebih banyak digunakan dalam penelitian pariwisata khususnya yang berhubungan dengan perencanaan ekowisata (Bunruamkaew \& Murayama, 2011), (Bunruamkaew \& Murayama, 2012) dan (Rahayuningsih et al., 2016) namun demikian SIG juga bisa dimanfaatkan untuk memberikan penilaian sumber daya visual dan manajemen, identifikasi lokasi yang cocok, dan bahkan telah digunakan dalam aplikasi yang berkaitan dengan pemasaran pariwisata (Riwayatiningsih \& Hartuti Purnaweni, 2017). 
Teknologi SIG diharapkan mampu menganalisis aspek ruang pada suatu daerah sehingga potensi-potensi wisata yang ada dapat dikembangkan menjadi daya tarik wisata secara optimal yang dapat menarik kunjungan wisatawan baik domestik maupun mancanegara. Penelitian ini bertujuan untuk menentukan pengembangan destinasi wisata Kawasan Kaldera Batur dengan pendekatan Sistem Informasi Geografis (SIG). Sementara secara khusus, penelitian ini akan mengidentifikasi arah pengembangan destinasi wisata khususnya fasilitas pendukung pariwisata berdasarkan kemampuan lahan Kawasan Kaldera Batur.

\section{METODE PENELITIAN}

Penelitian ini dilakukan untuk mengetahui arah pengembangan fasilitas penunjang pariwisata pada Kawasan Kaldera Batur dengan pendekatan Sistem Informasi Geografis (SIG). Ada 3 tahap yang dilakukan dalam penelitian ini, yaitu 1) identifikasi karakteristik fisik dan lingkungan pada Kawasan Kaldera Batur; 2) Memberikan bobot/skor untuk masingmasing unit lahan dengan karakteristik fisik dan lingkungannya masing-masing; dan 3) Analisis Overlay kondisi lahan di Kawasan Kaldera Batur berdasarkan skor unit lahan yang sudah dilakaukan sebelumnya. Analisis skoring dan overlay ini dilakukan dengan menggunakan Aplikasi ArcGis, dimana setiap informasi (kondisi morfologi lahan, curah hujan, jenis tanah, kemiringan lahan, kondisi geologi, dan kondisi hidrologi) dituangkan ke dalam peta tematik dan selanjutnya diberi nilai.

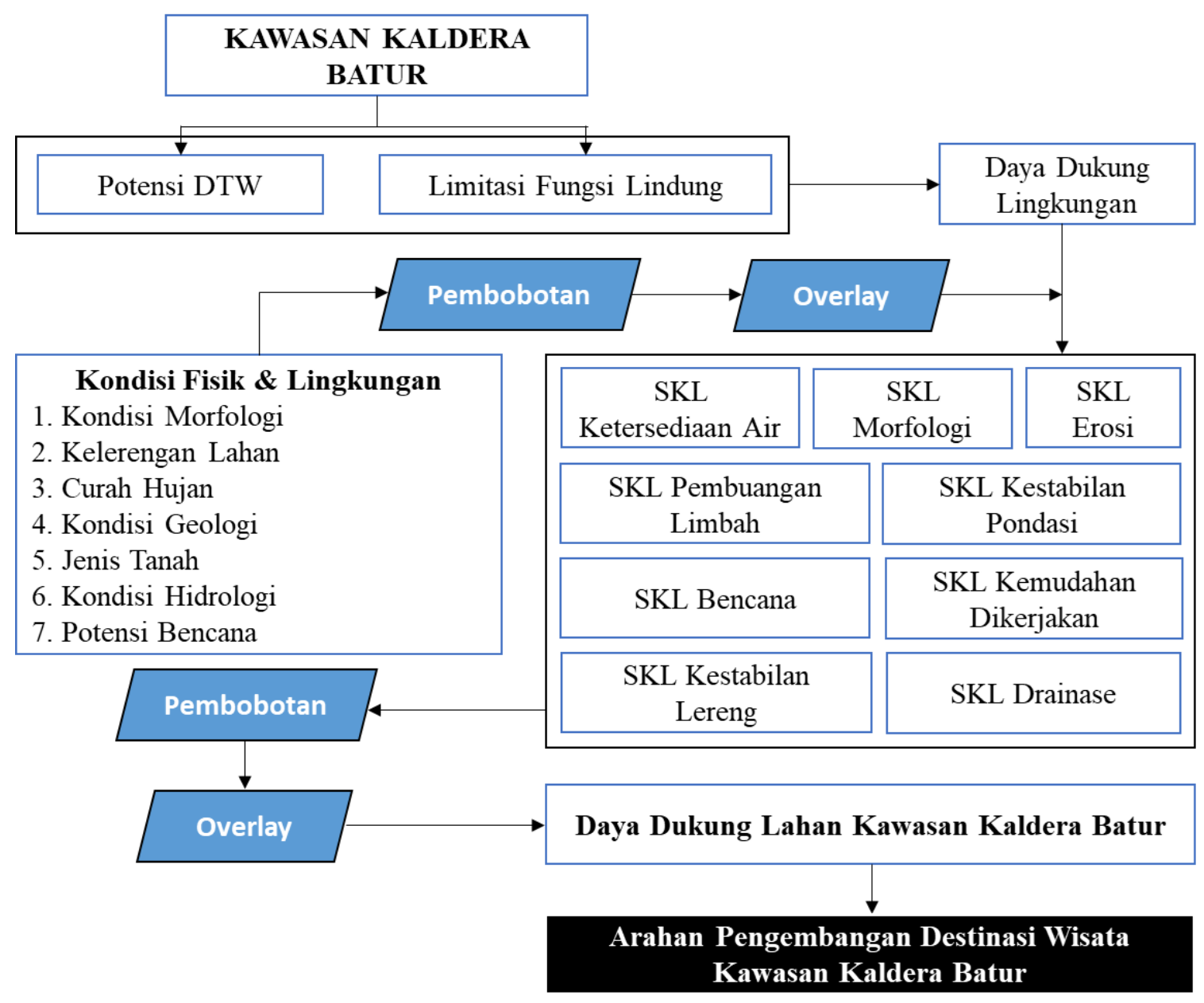

Gambar 1. Kerangka Berfikir 
Untuk membatasi dan memperjelas masalah yang diteliti, maka secara operasional masing-masing variabel dari masalah yang diteliti dapat dijelaskan sebagai berikut :

Tabel 1. Variabel Peneltian

\begin{tabular}{|c|c|c|}
\hline No & Variabel Penelitian & Keterangan \\
\hline 1 & kemampuan lahan dalam hal morfologi & $\begin{array}{l}\text { Untuk mengetahui karakteristik } \\
\text { kemampuan lahan dalam hal morfologi } \\
\text { maka variable yang digunakan untuk } \\
\text { menilai adalah kondisi morfologi lahan } \\
\text { dan kelerengan lahan }\end{array}$ \\
\hline 2 & $\begin{array}{l}\text { Kemampuan lahan dalam hal kemudahan } \\
\text { dikerjakan }\end{array}$ & $\begin{array}{l}\text { Untuk mengetahui karakteristik } \\
\text { kemampuan lahan dalam hal kemudahan } \\
\text { dikerjakan maka variable yang digunakan } \\
\text { untuk menilai adalah kondisi morfologi } \\
\text { lahan, geologi dan kelerengan lahan }\end{array}$ \\
\hline 3 & $\begin{array}{l}\text { Kemampuan lahan dalam hal kestabilan } \\
\text { lereng }\end{array}$ & $\begin{array}{l}\text { Untuk mengetahui karakteristik } \\
\text { kemampuan lahan dalam hal kestabilan } \\
\text { lereng maka variable yang digunakan } \\
\text { untuk menilai adalah kondisi jenis tanah, } \\
\text { kelerengan lahan, geologi dan curah } \\
\text { hujan }\end{array}$ \\
\hline 4 & $\begin{array}{l}\text { Kemampuan lahan dalam hal kestabilan } \\
\text { pondasi }\end{array}$ & $\begin{array}{l}\text { Untuk mengetahui karakteristik } \\
\text { kemampuan lahan dalam hal kestabilan } \\
\text { pondasi maka variable yang digunakan } \\
\text { untuk menilai adalah kondisi hidrologi } \\
\text { lahan dan kelerengan lahan }\end{array}$ \\
\hline 5 & $\begin{array}{l}\text { Kemampuan lahan dalam hal } \\
\text { ketersediaan air }\end{array}$ & $\begin{array}{l}\text { Untuk mengetahui karakteristik } \\
\text { kemampuan lahan dalam hal keterediaan } \\
\text { air maka variable yang digunakan untuk } \\
\text { menilai adalah kondisi curah hujan dan } \\
\text { hidrologi; }\end{array}$ \\
\hline 6 & Kemampuan lahan dalam hal drainase & $\begin{array}{l}\text { Untuk mengetahui karakteristik } \\
\text { kemampuan lahan dalam hal drainase } \\
\text { maka variable yang digunakan untuk } \\
\text { menilai adalah kondisi curah hujan, } \\
\text { lereng, jenis tanah dan geologi }\end{array}$ \\
\hline 7 & Kemampuan lahan dalam hal erosi & $\begin{array}{l}\text { Untuk mengetahui karakteristik } \\
\text { kemampuan lahan dalam hal drainase } \\
\text { maka variable yang digunakan untuk } \\
\text { menilai adalah kondisi curah hujan, } \\
\text { lereng, jenis tanah dan geologi }\end{array}$ \\
\hline 8 & Kemampuan lahan dalam hal & Untuk mengetahui karakteristik \\
\hline
\end{tabular}




\begin{tabular}{|c|l|l|}
\hline No & \multicolumn{1}{|c|}{ Variabel Penelitian } & \multicolumn{1}{c|}{ Keterangan } \\
\hline & pembuangan limbah & $\begin{array}{l}\text { kemampuan lahan dalam hal drainase } \\
\text { maka variable yang digunakan untuk } \\
\text { menilai adalah kondisi curah hujan, } \\
\text { lereng, jenis tanah dan geologi }\end{array}$ \\
\hline 9 & $\begin{array}{l}\text { Kemampuan lahan dalam hal bencana } \\
\text { alam }\end{array}$ & $\begin{array}{l}\text { Untuk mengetahui karakteristik } \\
\text { kemampuan lahan dalam hal drainase } \\
\text { maka variable yang digunakan untuk } \\
\text { menilai adalah tingkat kerentanan } \\
\text { gerakan tanah, Kawasan rawan bencana } \\
\text { gunung api, dan kelerengan lahan }\end{array}$ \\
\hline
\end{tabular}

Sumber : Hasil Analisis

Pengumpulan data pada penelitian ini dilakukan dengan 2 cara yaitu suvey primer dan survey sekunder. Survey primer dilakukan dengan observasi, dokumentasi dan pencatatan data. Survey sekunder dilakukan dengan melakukan pencarian data sekunder melalui instansi-instansi terkait dan kajian terhadap literature. Data yang digunakan meliputi potensi daya tarik wisata dan persebarannya secara spasial dan data kondisi fisik lingkungan (kondisi morfologi lahan, curah hujan, jenis tanah, kemiringan lahan, kondisi geologi, dan kondisi hidrologi). Lebih jelasnya kebutuhan data untuk penelitian ini dijabarkan dalam tabel berikut.

Tabel 2. Jenis dan Sumber Data

\begin{tabular}{|c|c|c|c|}
\hline No & Data & Sumber & Keterangan \\
\hline 1. & $\begin{array}{l}\text { Potensi Daya Tarik Wisata } \\
\text { dan persebarannya secara } \\
\text { spasial }\end{array}$ & $\begin{array}{l}\text { Dinas Pariwisata } \\
\text { Kabupaten Bangli; } \\
\text { Survey Primer }\end{array}$ & $\begin{array}{l}\text { Potensi daya tarik } \\
\text { wisata yang } \\
\text { diidentifikasi } \\
\text { berdasarkan SK Bupati } \\
\text { Bangli tentang } \\
\text { pengemangan daya tarik } \\
\text { wisata di Kawasan } \\
\text { Kaldera Batur. } \\
\text { Persebaran daya tarik } \\
\text { wisata dan fasilitas } \\
\text { penunjang pariwisata }\end{array}$ \\
\hline 2. & Kondisi Morfologi Lahan & $\begin{array}{l}\text { * Bappeda Litbang } \\
\text { Dinas PUPR }\end{array}$ & $\begin{array}{l}\text { Data morfologi lahan di } \\
\text { Wilayah Penelitian }\end{array}$ \\
\hline 3 & Kondisi Kelerengan Lahan & $\begin{array}{l}\text { Bappeda Litbang } \\
\text { Dinas PUPR } \\
\text { Dinas ESDM }\end{array}$ & $\begin{array}{l}\text { Data kelerengan lahan di } \\
\text { Wilayah Penelitian }\end{array}$ \\
\hline 4. & Curah Hujan & $\begin{array}{l}\text { Badan Meteorologi } \\
\text { dan Geofisika }\end{array}$ & $\begin{array}{l}\text { Data curah hujan harian } \\
\text { dan tahunan di wilayah } \\
\text { penelitian }\end{array}$ \\
\hline 5. & Kondisi Geologi & $\begin{array}{l}\text { * Bappeda Litbang } \\
\text { Dinas PUPR }\end{array}$ & $\begin{array}{l}\text { Data kondisi geologi lahan } \\
\text { di Wilayah Penelitian }\end{array}$ \\
\hline
\end{tabular}




\begin{tabular}{|c|c|c|c|}
\hline No & Data & Sumber & Keterangan \\
\hline & & * Dinas ESDM & \\
\hline 6. & Jenis Tanah & $\begin{array}{l}\text { Bappeda Litbang } \\
\text { Dinas PUPR } \\
\text { Dinas ESDM }\end{array}$ & $\begin{array}{l}\text { Data jenis tanah yang ada } \\
\text { di Wilayah Penelitian }\end{array}$ \\
\hline 7. & Kondisi Hidrologi Wilayah & $\begin{array}{l}\text { Bappeda Litbang } \\
\text { Dinas PUPR } \\
\text { Dinas ESDM }\end{array}$ & $\begin{array}{l}\text { Kondisi hidrologi wilayah } \\
\text { yang meliputi kandungan } \\
\text { air tanah di wilayah } \\
\text { Penelitian }\end{array}$ \\
\hline 8. & Potensi Bencana & $\begin{array}{ll}* & \text { BPBD Provinsi } \\
\text { Bali } \\
* \text { BPBD Kabupaten } \\
\text { Bangli }\end{array}$ & $\begin{array}{l}\text { Kondisi potensi } \\
\text { kebencanaan di Kawasan } \\
\text { Kaldera Batur meliputi } \\
\text { potensi Gerakan tanah dan } \\
\text { zona Kawasan rawan } \\
\text { bencana gunung api }\end{array}$ \\
\hline
\end{tabular}

Sumber : Hasil Analisis

Data yang diperoleh melalui pengumpulan data akan ditabulasikan dan kemudian dioleh dengan menggunakan aplikasi ArcGis. Pengolahan data hasil observasi lapangan (survey primer dan sekunder) akan ditabulasikan dan kemudian diberikan nilai (scoring) berdasarkan karakteristik kondisi fisik dan lingkungan di wilayah penelitian. Data hasil scoring kemudian dijadikan input untuk proses analisis selanjutnya yang akan dilakukan melalui aplikasi ArcGis dengan metode overlay, sehingga diperoleh nilai akhir yang merupakan score kesesuaian lahan terhadap pengembangan fasilitas penunjang pariwisata di Kawasan Kaldera Batur.

\section{HASIL DAN PEMBAHASAN}

Persebaran Daya Tarik Wisata dan Fasilitas Penunjang Pariwisata di Kawasan Kaldera Batur

Daya Tarik Wisata (DTW) pada Kawasan Kaldera Batur berdasarkan Sumber : Kepbup 556/202/2014 tentang Penetapan DTW yang dikembangkan dan DTW yang dikenakan retribusi di Kabupaten Bangli terbagi menjadi 3 (tiga) kategori yakni: Daya Tarik Wisata (DTW) sudah berkembang, Daya Tarik Wisata (DTW) sedang berkembang, dan Daya Tarik Wisata (DTW) akan dikembangkan. Daya tarik wisata tersebut meliputi:

Tabel 3. Daya Tarik Wisata di Kawasan Kaldera Batur

\begin{tabular}{|c|c|c|c|c|}
\hline \multirow{2}{*}{ No } & \multirow{2}{*}{ DTW } & \multicolumn{2}{|c|}{ Lokasi } & \multirow[t]{2}{*}{ Jenis } \\
\hline & & Desa & Kecamatan & \\
\hline $\mathbf{A}$ & \multicolumn{4}{|l|}{ SUDAH BERKEMBANG } \\
\hline 1 & Pura Penulisan & Sukawana & Kintamani & Wisata Budaya \\
\hline 2 & Batur & Batur & Kintamani & Wisata Alam \\
\hline 3 & Trunyan & Trunyan & Kintamani & Wisata Budaya \\
\hline B & \multicolumn{4}{|l|}{ SEDANG BERKEMBANG } \\
\hline 1 & Museum Gunung Api Batur & Kedisan & Kintamani & Wisata Geologi \\
\hline
\end{tabular}




\begin{tabular}{|c|c|c|c|c|}
\hline \multirow{2}{*}{ No } & \multirow{2}{*}{ DTW } & \multicolumn{2}{|c|}{ Lokasi } & \multirow[t]{2}{*}{ Jenis } \\
\hline & & Desa & Kecamatan & \\
\hline $\mathbf{C}$ & \multicolumn{4}{|c|}{ AKAN DIKEMBANGKAN } \\
\hline 1 & Dalem Balingkang & Pinggan & Kintamani & Wisata Budaya \\
\hline 2 & Air Terjun Yeh Mampeh & Batur & Kintamani & Wisata Alam \\
\hline 3 & Desa Songan & Songan & Kintamani & Wisata Alam \\
\hline 4 & Hutan Wisata Suter & Suter & Kintamani & Wisata Alam \\
\hline
\end{tabular}

Sumber: RIPPDA Kabupaten Bangli

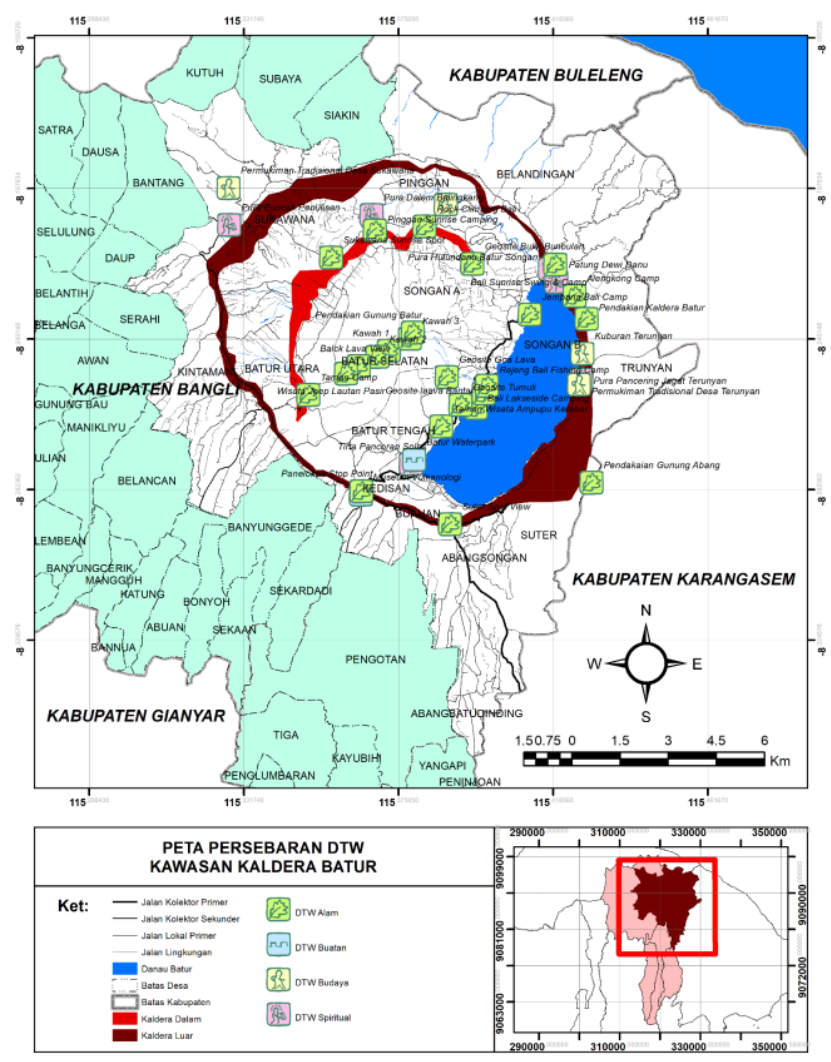

Gambar 2. Persebaran Daya Tarik Wisata di Kawasan Kaldera Batur

Berdasarkan hasil observasi terhadap DTW yang ada di Kawasan Kaldera Batur maka jenis DTW dapat dikelompokan menjadi DTW Kluster Spiritual, DTW Kluster Budaya, DTW Kluster Alama, dan DTW Kluster Buatan. Sebagain besar DTW yang ada di wilayah penelitian ini termasuk ke dalam kategori DTW Kluster alam yang meliputi Gunung Batur dan ketiga kawah, Kaldera dalam dan Kaldera Luar yang mengelilingi Kawasan Kaldera Batur, Danau, berbagai jenis geosite dan asset vista/view yang memanfaatkan kondisi alam di yang masih hijau, bebatuan, lava, bukit dan gunung dan juga kesejukan udara. DTW Kluster Spiritual di wilayah penelitian meliputi Pura Puncak Penulisan, Pura Dalem Balingkang, Pura Hulundanu Batur Songan, Pura Pancering Jagat Terunyan, dan Pura Ulundanu Batur. DTW Kluster Budaya meliputi permukiman tradisional Desa Sukawana, permukiman tradisional permukiman Desa Pinggan dan permukiman tradisional Desa Terunyan. DTW Kluster Buatan meliputi spot-spo foto, museum gunung api dan taman bermain. 

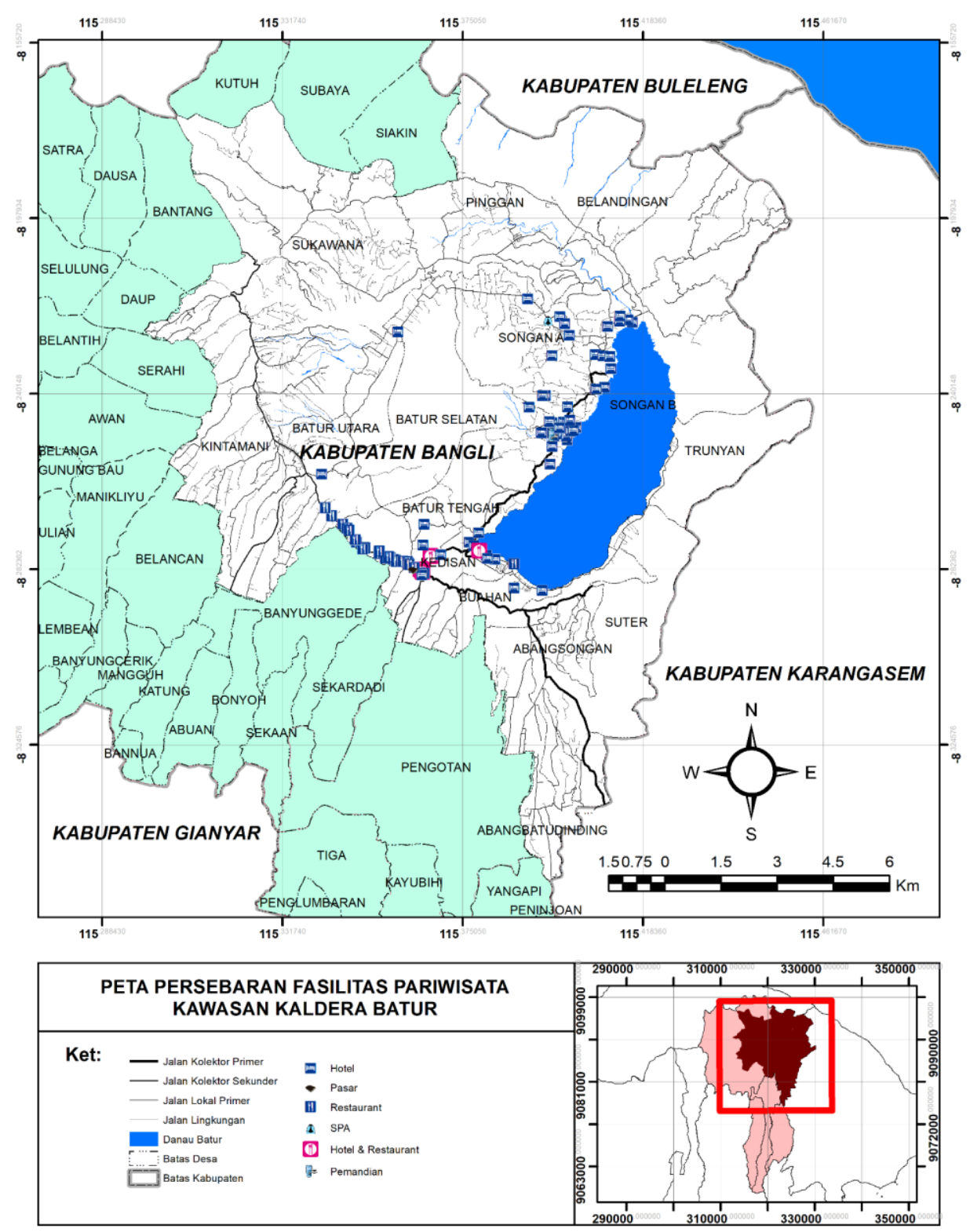

Gambar 3. Persebaran Fasilitas Penunjang Pariwisata di Kawasan Kaldera Batur

Berdasarkan hasil observasi terhadap berbagai jenis fasilitas penunjang pariwisata di Kawasan Kaldera Batur, maka jenis fasilitas pariwisata yang berkembang pada Kawasan ini meliputi Hotel, Restoran, Pasar Seni, SPA dan Pemandian Air Panas. Fasilitas pariwisata ini sebagian besar tersebar di Desa Batur Tengah, Batur Selatan, Kedisan Buahan, Songan A dan Desa Songan B.

\section{Arahan Pengembangan Fasilitas Pariwisata di Kawasan Kaldera Batur}

Arahan pengembangan fasilitas pariwisata di Kawasan Kaldera Batur ditentukan dengan pendekatan kemampuan lahan untuk kawasan terbangun yang dimodifikasi dari pedoman analisis kawasan budidaya Permen PU No. 20 Tahun 2007. Analisis Kemampuan Lahan (AKL) dilakukan dengan menggunakan metode overlay beberapa data karakteristik lahan sehingga dihasilkan Satuan Kemampuan lahan (SKL) tematik yang nantinya digunakan sebagai input untuk analisis overlay selanjutnya. Analisis ini dilakukkan untuk memperoleh gambaran tingkat kemampuan lahan sehingga bisa menjadi rekomendasi untuk pengembangan fasilitas penunjang pariwisata pada Kawasan Kaldera Batur. Sesuai dengan 
Permen PU No. 20 Tahun 2007 analisis kemampuan lahan dilakukan untuk mengetahui arahan kawasan budidaya pada suatu wilayah. Fasilitas penunjang pariwisata merupakan bagian dari Kawasan budidaya, sehingga analisis kemampuan lahan ini merupakan salah satu metode yang tepat digunaakn untuk menghitung unit-unit lahan yang sesuai untuk Kawasan terbangun dalam hal ini adalah fasilitas penunjang pariwisata.

Data yang digunakan dalam AKL adalah peta hasil analisis SKL yang terdiri dari SKL Morfologi, SKL Kemudahan Dikerjakan, SKL Kestabilan Lereng, SKL Kestabilan Pondasi, SKL Ketersediaan Air, SKL Drainase, SKL Erosi, SKL Pembuangan Limbah dan SKL Bencana Alam. Peta hasil analisis SKL diperoleh melalui hasil overlay beberapa data kondisi fisik lingkungan yang sebelumnya sudah diberikan bobot/skor sesuai dengan kondisi fisik lingkungan masing-masing unit lahan tersebut. Berikut ini adalah hasil analisis overlay untuk SKL tematik.
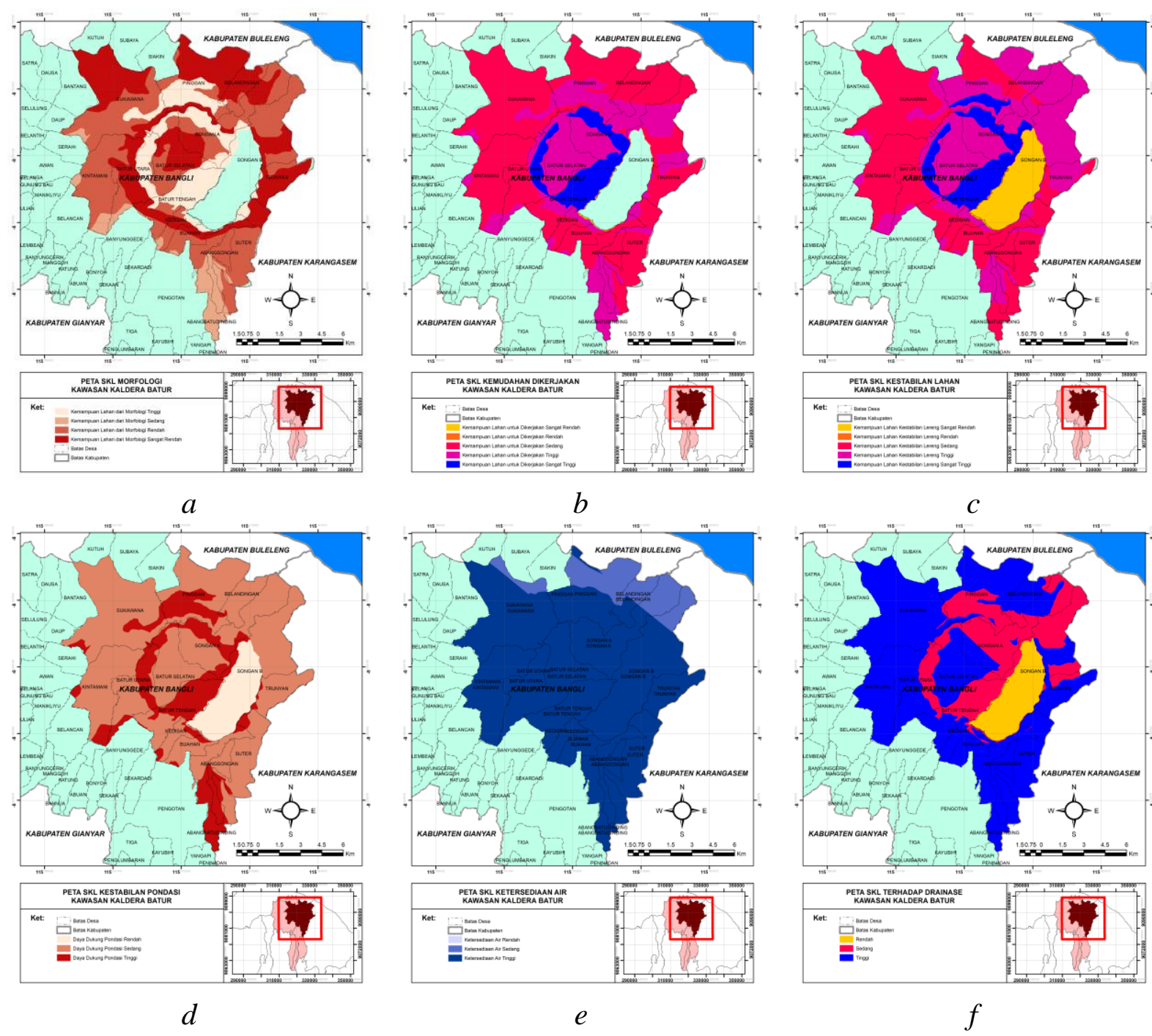

Gambar 4. Hasil Analisis Kemampuan Lahan 

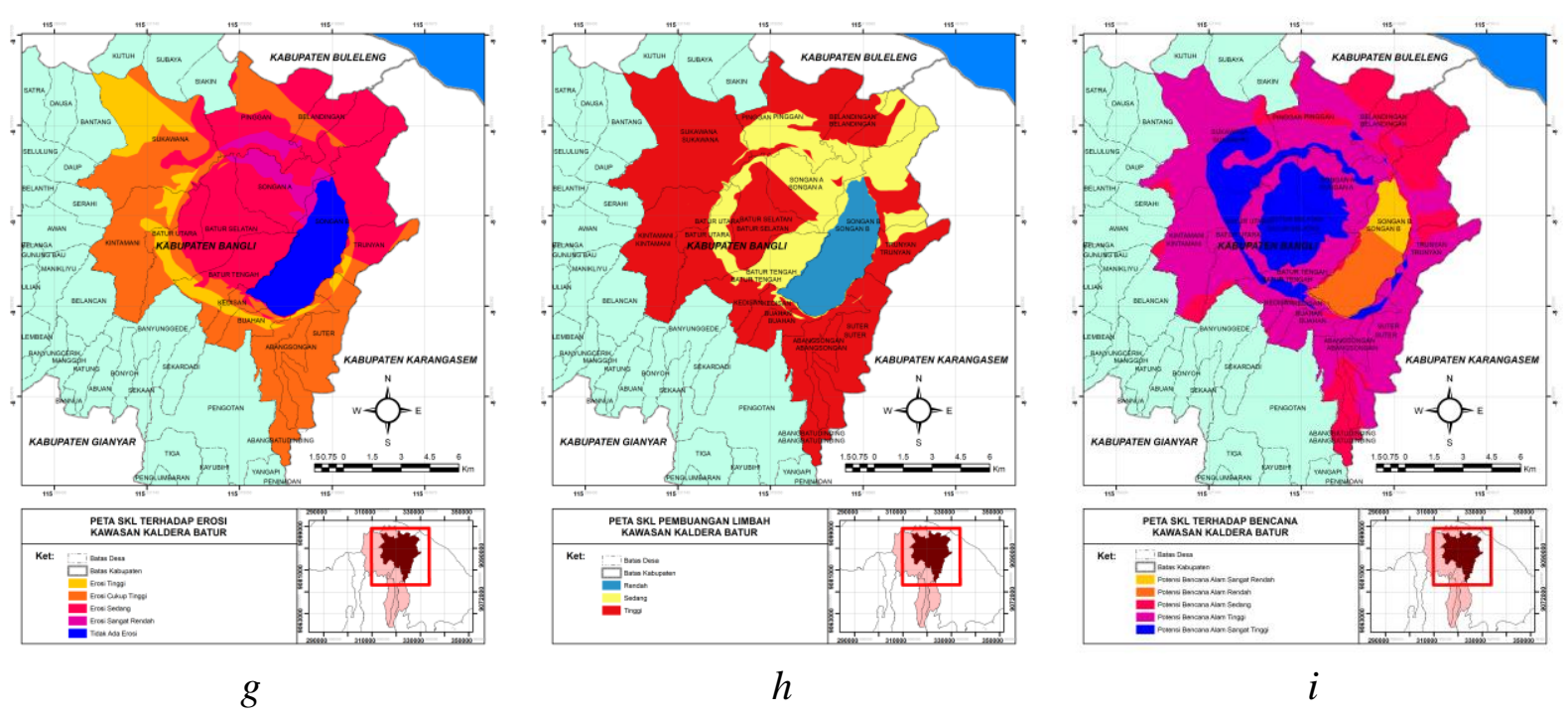

Gambar 5. Hasil Analisis Kemampuan Lahan (lanjutan)

Hasil analisis overlay terhadap variable kondisi morfologi lahan, curah hujan, jenis tanah, kemiringan lahan, kondisi geologi, kondisi hidrologi dan potensi kebencanaan menghasilkan satuan kemampuan lahan tematik seperti pada gambar di atas, yaitu (a) satuan kemampuan lahan morfologi yang menunjukan tingkat kemampuan lahan untuk dikembangkan sebagai fasilitas pariwisata dari segi morfologi lahan; (b) satuan kemampuan lahan kemudahan dikerjakan menunjukan kemampuan lahan untuk dikembangkan berdasarkan kemudahan lahan tersebut untuk dibangun; (c) satuan kemapuan lahan kestabilan lereng menunjukan kemampuan lahan dalam hal kekuatan lereng untuk dibangun; (d) satuan kemampuan lahan kestabilan pondasi menunjukan seberapa kuat pondasi lahan jika dikembangkan sebagai kawsan terbangun; (e) satuan kemampuan lahan ketersediaan air menunjukan tingkat kemampuan lahan dalamm menyediakan air jika dikembangkan sebagai kawasan budidaya; (f) satuan kemampuan lahan drainase menunjukan kemampuan lahan dalam hal mengalirkan air buang; (g) satuan kemampuan lahan erosi menunjukan tingkat kemampuan lahan terhadap erosi; (h) satuan kemampuan lahan pembuangan limbah menunjukan tingkat kemampuan lahan dalam pembungan limb ah cair dan (i) satuan kemampuan lahan bencana menunjukan kemampuan lahan dalam hal kerentanan terhadap bencana.

Masing-masing peta SKL tematik yang sudah dihitung dengan analisis overlay selanjuttnya dibobotkan kembali untuk selanjutnya dilakukan analisis overlay untuk menentukan kemampuan lahan gabungan. Berikut ini adalah pembobotan untuk masingmasing SKL.

Tabel 4. Analisis Kemampuan Lahan

\begin{tabular}{|c|c|c|c|c|c|}
\cline { 2 - 6 } \multicolumn{1}{c|}{} & $\begin{array}{c}\text { SKL } \\
\text { Morfologi }\end{array}$ & $\begin{array}{c}\text { SKL } \\
\text { Kemudahan } \\
\text { Dikerjakan }\end{array}$ & $\begin{array}{c}\text { SKL } \\
\text { Kestabilan } \\
\text { Lereng }\end{array}$ & $\begin{array}{c}\text { SKL } \\
\text { Kestabilan } \\
\text { Pondasi }\end{array}$ & $\begin{array}{c}\text { SKL } \\
\text { Ketersediaan } \\
\text { Air }\end{array}$ \\
\cline { 2 - 6 } & Bobot $: 5$ & Bobot $: 1$ & Bobot $: 5$ & Bobot $: 3$ & Bobot $: 5$ \\
\hline $\begin{array}{c}\text { Bobot } \\
\text { X }\end{array}$ & 5 & 1 & 5 & 3 & 5 \\
\cline { 2 - 6 } Nilai & 10 & 2 & 10 & 6 & 10 \\
\cline { 2 - 6 } & 20 & 3 & 15 & 9 & 15 \\
\hline
\end{tabular}




\begin{tabular}{|l|l|l|l|l|l|}
\hline & 25 & 5 & 25 & 15 & 25 \\
\hline
\end{tabular}

Sumber: Permen PU No. 20 Tahun 2007

Tabel 5. Analisis Kemampuan Lahan (lanjutan)

\begin{tabular}{|c|c|c|c|c|c|}
\cline { 2 - 6 } \multicolumn{1}{c|}{} & $\begin{array}{c}\text { SKL } \\
\text { untuk } \\
\text { Drainase }\end{array}$ & $\begin{array}{c}\text { SKL } \\
\text { terhadap } \\
\text { Erosi }\end{array}$ & $\begin{array}{c}\text { SKL } \\
\text { Pembuangan } \\
\text { Limbah }\end{array}$ & $\begin{array}{c}\text { SKL } \\
\text { Bencana } \\
\text { Alam }\end{array}$ & $\begin{array}{c}\text { Kemampuan } \\
\text { Lahan }\end{array}$ \\
\cline { 2 - 6 } & $\begin{array}{c}\text { Bobot : } \\
5\end{array}$ & $\begin{array}{c}\text { Bobot : } \\
3\end{array}$ & Bobot : 0 & $\begin{array}{c}\text { Bobot : } \\
5\end{array}$ & Total Nilai \\
\hline \multirow{3}{*}{$\begin{array}{c}\text { Bobot } \\
\text { X }\end{array}$} & 5 & 3 & 0 & 3 & $\mathbf{3 2}$ \\
\cline { 2 - 6 } Nilai & 10 & 6 & 0 & 6 & $\mathbf{6 4}$ \\
\cline { 2 - 6 } & 20 & 15 & 0 & 9 & $\mathbf{9 6}$ \\
\cline { 2 - 6 } & 25 & 15 & 0 & 12 & $\mathbf{1 6 0}$ \\
\hline
\end{tabular}

Sumber: Permen PU No. 20 Tahun 2007

Dari total nilai dibuat beberapa kelas yang memperhatikan nilai minimum dan maksimum total nilai. Dari angka di atas, nilai minimum yang mungkin diperoleh adalah 32 sedangkan nilai maksimum yang dapat diperoleh adalah 160. Dengan demikian, klasifikasi kemampuan lahan pada Kawasan Kaldera Batur dapat dibuat sebagai berikut.

Tabel 6. Klasifikasi Kelas Kemampuan Lahan

\begin{tabular}{|c|c|c|l|}
\hline No & Total Nilai & $\begin{array}{c}\text { Kelas } \\
\text { Kemampuan } \\
\text { Lahan }\end{array}$ & \multicolumn{1}{|c|}{ Klasifikasi Pengembangan } \\
\hline 1 & $32-58$ & Kelas A & $\begin{array}{l}\text { Kemampuan pengembangan lahan } \\
\text { sangat rendah }\end{array}$ \\
\hline 2 & $59-83$ & Kelas B & $\begin{array}{l}\text { Kemampuan pengembangan lahan } \\
\text { rendah }\end{array}$ \\
\hline 3 & $84-109$ & Kelas C & $\begin{array}{l}\text { Kemampuan pengembangan lahan } \\
\text { sedang }\end{array}$ \\
\hline 4 & $110-134$ & Kelas D & $\begin{array}{l}\text { Kemampuan pengembangan lahan } \\
\text { agak tinggi }\end{array}$ \\
\hline 5 & $135-160$ & Kelas E & $\begin{array}{l}\text { Kemampuan pengembangan lahan } \\
\text { sangat tinggi }\end{array}$ \\
\hline
\end{tabular}

Sumber : Hasil Analisis 2019

Hasil analisis menunjukan bahwa, kelas kemampuan lahan di Kawasan Kaldera Batur terdiri dari :

1. Kelas B yaitu kemampuan pengembangan lahan untuk fasilitas penunjang pariwisata dengan klasifikasi rendah seluas $1.50,95 \mathrm{Ha}$ atau $8,52 \%$.

2. Kelas $\mathrm{C}$ yaitu kemampuan pengembangan lahan untuk fasilitas penunjang pariwisata pariwisata dengan klasifikasi sedang seluas 3.641,91 Ha atau 18,78\%.

3. Kelas D yaitu kemampuan pengembangan lahan untuk fasilitas penunjang pariwisata pariwisata dengan klasifikasi agak tinggi seluas 8.603,97 Ha atau 44,37\%. 
4. Kelas E yaitu kemampuan pengembangan lahan untuk fasilitas penunjang pariwisata pariwisata dengan klasifikasi sangat tinggi seluas 5.493,47 Ha atau 28,33\%.

Hasil analisis ini juga menunjukkan bahwa daya dukung lahan di Kawasan Kaldera Batur didominasi oleh lahan yang termasuk kedalam Kelas D yaitu kemampuan pengembangan lahan untuk fasilitas penunjang pariwisata dengan klasifikasi agak tinggi dan Kelas E yaitu kemampuan pengembangan lahan untuk penunjang fasilitas pariwisata dengan klasifikasi sangat tinggi. Pengembangan Destinasi Pariwisata khususnya dalam hal penyediaan berbagai fasilitas penunjang pariwisata harus diarahkan pada unit-unit lahan dengan klasifikasi daya dukung lahan kelas E yang tersebar di Desa Sukawana dengan luas 839 Ha, Desa Batur 1.266 Ha, Desa Batur Tengah dengan luas 820 Ha, Desa Songan A 767 Ha, dan Desa Abangsongan dengan luas $108 \mathrm{Ha}$. Arahan rasio tutupan lahan untuk daya dukung lahan kelas $\mathrm{E}$ adalah maksimal $30 \%$ dari luas lahan yang akan dibangun dengan ketinggian bangunan maksimal adalah 3 lantai sedangkan arahan rasio tutupan lahan untuk daya dukung lahan kelas D adalah maksimal $20 \%$ dari luas lahan yang akan dibangun dengan ketinggian bangunan maksimal adalah 3 lantai (Permen PU No. 20 Tahun 2007).

\section{SIMPULAN}

Hasil analisis menunjukkan bahwa kemampuan lahan di Kawasan Kaldera Batur didominasi oleh lahan yang termasuk dalam Kelas D yaitu kemampuan pengembangan agak tinggi dan Kelas E yaitu kemampuan pengembangan sangat tinggi. Berdasarkan hasil analisis kemampuan lahan yang ditunjukan oleh Gambar 4.23 diketahui bahwa arahan pengembangan penyediaan fasilitas penunjang pariwisata adalah seluas $14.096 \mathrm{Ha}$ yang sebagian besar tersebar di Desa Batur Tengah, Batur Selatan, Songan A, Sukawana dan Abangbatudinding.

\section{REFERENSI}

Aronoff, S. (1989). A Review of Geographic Information System : a management perspective. Ottawa: WDL Publications. pp.294.

Badan Pusat Statistik Provinsi Bali. 2017. Statistik Pariwisata Bali Tahun 2017. Denpasar : Badan Pusat Statistik

Bunruamkaew, K., \& Murayama, Y. (2011). Site Suitability Evaluation for Ecotourism Using GIS \& AHP : A Case Study of Surat Thani Province, Thailand. Journal of Procedia Social and Behavioral Science 21, 269-278. https://doi.org/10.1016/j.sbspro.2011.07.024

Bunruamkaew, K., \& Murayama, Y. (2012). Land Use and Natural Resources Planning for Sustainable Ecotourism Using GIS in Surat Thani, Thailand, Journal of Sustainability 4, 412-429. https://doi.org/10.3390/su4030412

Pitana, I Gede. 1998. Pembangunan Pariwisata Berkelanjutan. Makalah disampaikan pada seminar pariwisata regional PS. D4 Pariwisata UNUD.

Pitana, I Gde. dan Surya Diarta, I Ketut. 2009. Pengantar Ilmu Pariwisata. Yogyakarta: ANDI.

Prahasta, Eddy. (2006). Sistem Informasi geografis (Membangun Web Based GIS dengan Mapserver). Bandung: CV. Informatika.

Rahayuningsih, T., Muntasib, E. K. S. H., \& Budi, L. (2016). Nature Based Tourism Resources Assessment Using Geographic Information System ( GIS ): Case Study in Bogor. Journal Procedia Environmental 33, 365-375. https://doi.org/10.1016/j.proenv.2016.03.087

Republik Indonesia. 2009. Undang-Undang No. 10 Tahun 2009 Tentang Kepariwisataan. Lembaran Negara RI Tahun 2009, No. 11. Sekretariat Negara. Jakarta. 
Republik Indonesia. 2009. Undang-Undang Nomor 32 Tahun 2009 Tentang Perlindungan dan Pengelolaan Lingkungan Hidup. Lembaran Negara RI Tahun 2009, No. 4438. Sekretariat Negara. Jakarta.

Suprapto, Nyoman Arto; Osawa, Takahiro; Putra, I Dewa Nyoman Nurweda. 2018. Estimation of Green Land to Urban Change Based on Cellular Automata (CA) Method in Singaraja City and its Surrounding Areas. International Journal of Environment and Geosciences. 2(1): 1-8

Suprapto, Nyoman Arto dan Suryanto, Agus. 2019. Partisipasi Masyarakat dalam Pengembangan Homestay di Desa Wisata Pangsan Kabupaten Badung. Proceeding Seminar Riset Terapan Hospitality dan Kepariwisataan Indonesia 2019, Nusa Dua: 11 Juli 2019: Hal. 425 - 433

Suprapto, Nyoman Arto. (2010). Arahan Pengendalian Pembangunan Kawasan Cagar Budaya Candi Tebing Gunung Kawi Tampak Siring Kabupaten Gianyar. Tugas Akhir Program Studi Perencanaan Wilayah dan Kota Institut Teknologi Sepuluh November Surabaya.

Suprapto, Nyoman Arto. (2019). SPATIAL SIMULATION BASED ON GEOGRAPHIC INFORMATION SYSTEM (GIS) AND CELLULAR AUTOMATA (CA) FOR LAND USE CHANGE MODELING IN SINGARAJA CITY AND ITS SURROUNDING AREA. Tesis Program Magister Ilmu Lingkungan Universitas Udayana. 